\title{
FABRICATION OF THERMOELECTRIC ROOF TILES FOR POWER GENERATOR
}

\section{SAKORN INTHACHAI ${ }^{1}$, TOSAWAT SEETAWAN ${ }^{2}$, JINDAPORN JAMRADLOEDLUK $^{3} \&$ NATTADON PANNUCHAROENWONG ${ }^{4}$}

\footnotetext{
${ }^{1,3}$ Solar Energy and Energy Resources Research Unit, Faculty of Engineering, Mahasrakham University, Khamrieng,
} Kantarawichai, Maha Sarakham 44150, Thailand

${ }^{2}$ Program of Physics, Faculty of Science and Technology, Sakon Nakhon Rajabhat University, 680 Nittayo Road., Mueang District, Sakon Nakhon 47000, Thailand

${ }^{2}$ Thermoelectric Research Laboratory, Center of Excellence on Alternative Energy, Research and Development Institution, Sakon Nakhon Rajabhat University, 680 Nittayo Rd. Mueang District, Sakon Nakon Province, 47000, Thailand

${ }^{4}$ Department of Mechanical Engineering, Faculty of Engineering, Thammasat University, 99 Village No.18 Phahonyothin Road, Klongluang, Rangsit, Pathumthani, 12121, Thailand

\section{ABSTRACT}

The aim of this paper was to Fabrication of a new roof design concept termed "the thermoelectric roof tiles (RT-TEG)" for power generation using solar energy. The RT-TEG was composed of a top layer (CaCO3) has 2 mm of thickness for receive the heat from sunlight. The middle layer used for supporting 1 thermoelectric module (Model TEG-SP184827145SA). The bottom of thermoelectric module used the aluminium sheets for heat rejected. The lowest layer (CaCO3) was $2 \mathbf{~ m m}$ of thickness. The incident solar radiation heats up the copper plate so that a temperature difference is created between the TE module that generates a direct current. The RT-TEG surface area was 0.1386 $m$-2. The RT-TEG could generate about 1,150 $\square$ W at load resistance $1 \square$ and output voltage $41 \mathrm{mV}$ at velocity $1.5 \mathrm{~ms}-1$ and solar intensity of 1,000 Wm-2. Therefore, the proposed RT-TEG concept seems to be an interesting new alternative for various purposes such as power generation in remote areas, roof heat gain reduction and indoor ventilation of spaces.

KEYWORDS: Thermoelectric Roof Tiles, Power Generator, Thermoelectric Module

Received: Jun 10, 2020; Accepted: Jun 30, 2020; Published: Jul 27, 2020; Paper Id.: IJMPERDJUN2020475

\section{INTRODUCTION}

Global warming is internationally critical problem with a severe impact on the global climate change. One major cause of this problem is the human's consumption of the fossil fuel such as coal, oil, or natural for energy production that releases a lot of Carbon Dioxide, a cause of the greenhouse effect toward the earth's atmosphere [1].

Despite the current hydroelectricity production as a renewable energy source, there is only a few of that energy source as well as the water resource for electricity production; the water is still in shortage. For this reason, there is an effort to look for new sources of energy which is cost-saving and cannot be completely consumed. Actually, some of those energy sources have been already used in some foreign counties such as the tide, wave (sea), or oceanic heat. Still, there is some limits concerning the development of solar energy, wind power, and geothermal energy since it requires a very high cost, a large area for an installation, a long period of construction, or there are insufficient amount of those energy in some countries. 
As a consequence, it becomes even more necessary to invent a new method for electricity production to replace an old form of energy that seems to be surely in shortage in the future. In this regard, thermoelectric is one characteristics of a substance that can be applicably developed as an alternative energy. This is currently a highlight amongst many researchers.

In term of the use of Seebeck effect [3-6], a thermoelectric material can be modified as a thermoelectricity generator so it is possible to turn the electric power from a waste or an excessive heat from a man's routine e.g. the heat from the electric pot, a human body heat, as well as other natural heats such as solar heat, hot spring's heat, the heat from soil or the global warming, and use it to build a thermoelectric device as a thermoelectricity generator. Eventually, we can build and design several models of thermoelectric device from Material $\mathrm{P}$ and $\mathrm{N}$.

A novel concept in this study is proposed to combine the advantages ofRTand TE. The thermoelectric roof tiles (RT-TEG) is therefore developed to generate electrical power. This paper aims, mainly, at fabrication the ability of this new concept in power generation

\section{EXPERIMENTAL}

\section{Fabrication of RT-TEG}

The RT-TEG surface area was $0.1386 \mathrm{~m}-2$ in Fig. 1. The top layer $\left(\mathrm{CaCO}_{3}\right)$ has $2 \mathrm{~mm}$ of thickness for receive the heat from sunlight. The middle layer used for supporting 1 thermoelectric module (Model TEG-SP1848-27145SA). The bottom of thermoelectric module used the aluminum sheets for heat rejected. The lowest layer $\left(\mathrm{CaCO}_{3}\right)$ was $2 \mathrm{~mm}$ of thickness as shown in Fig. 2.

Practically, the RT-TEG were installed at the Center of Excellence on Alternative Energy, Research and Development Institution, SakonNakhonRajabhat University, Thailand and the installation procedure was described in Fig. 3. The instrumentation in the test set-up included sensors for temperature, solar radiation, air, velocity and power output. The distribution of the sensors is shown in Fig. 3. A hot wire anemometer (range: $0-10 \mathrm{~m} / \mathrm{s}, \pm 0.05 \mathrm{~m} / \mathrm{s}$ ) was used to measure the air velocity. Thermocouples of type $\mathrm{K}$ (range: $0-200{ }^{\circ} \mathrm{C}, \pm 0.5 \%$ ) were used to measure the surface temperature of thermoelectric roof tiles at two points; the hot and the cold sides of thermoelectric module assembly at four points. A data acquisition system was used to collect the data at every $30 \mathrm{~min}$ interval. The experimental work reported here focuses mainly on testing the performance of the daytime solar thermoelectric power generation.

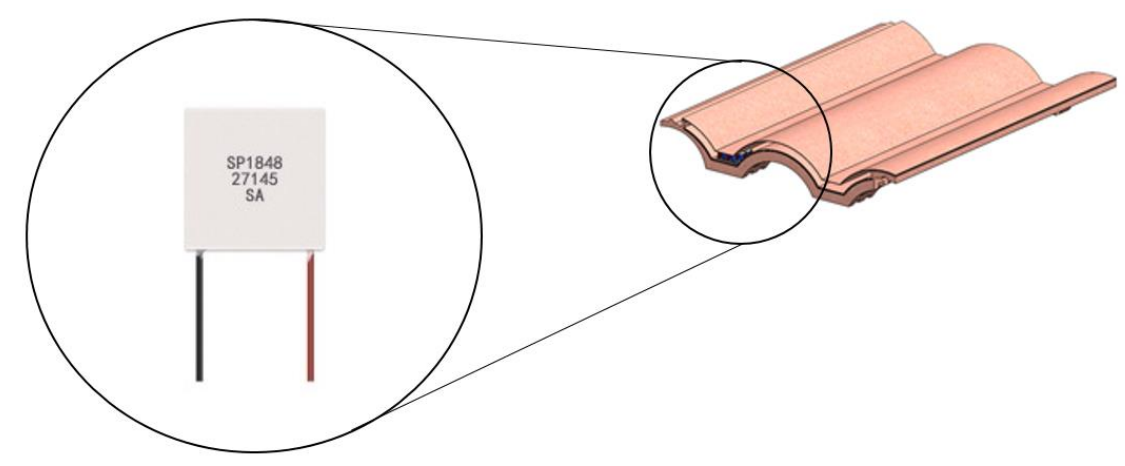

Figure 1: Schematicre Presentation of the RT-TEG. 


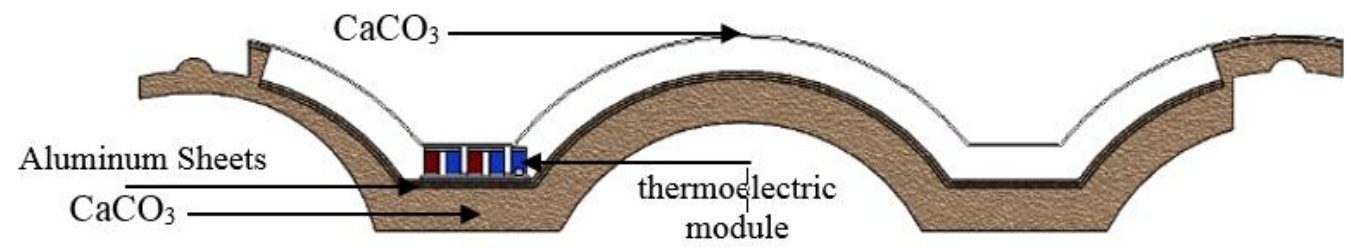

Figure 2: Schematic Diagram Illustrating the Basic Operation of the RT-TEG.

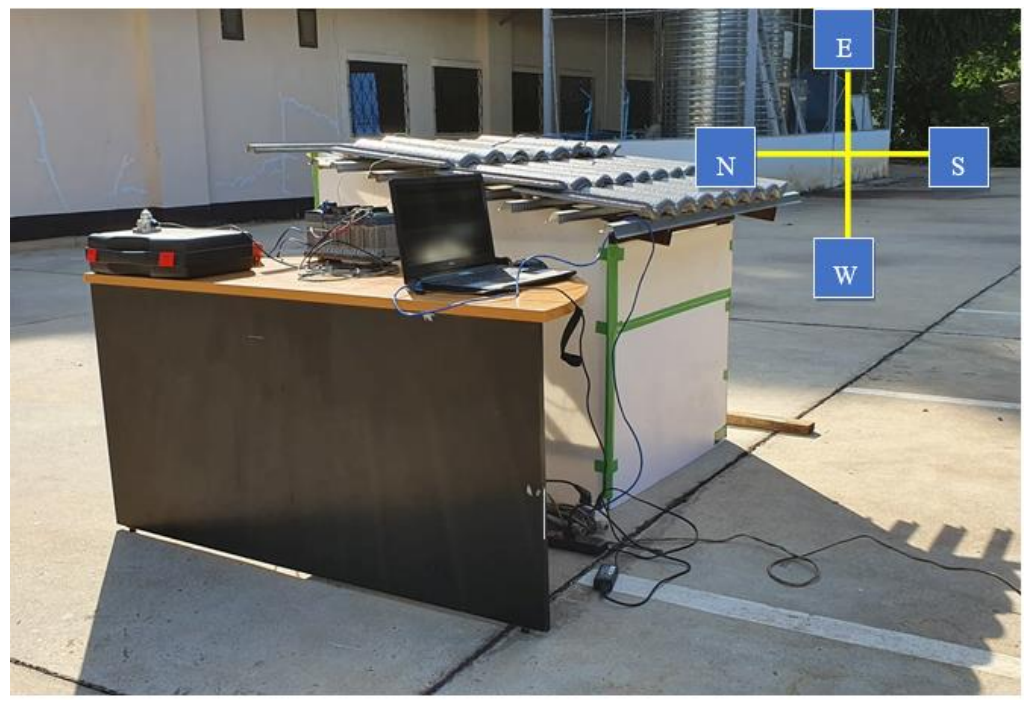

Figure 3: The Field Test Set-Up of the RT-TEG.

\section{RESULTS AND DISCUSSIONS}

\section{System Performance}

The open circuit voltage was illustrated in Fig. 4. It was found that the output voltage was increases with temperature increasing and a maximum value about $41 \mathrm{mV}$ at velocity $1.5 \mathrm{~ms}-1$. Fig. 5 describes the relationships between daylight solar radiation and temperature in RT-TEG during the experimental test composed of top side temperature, bottom side temperature, and temperature difference created. The solar radiation ranged on daylight start about $200 \mathrm{Wm}-2$ at 07.00 O'clock can create temperature difference $1 \mathrm{~K}$ after that the radiation increased to a maximum of about $1,000 \mathrm{~W} \cdot \mathrm{m}-2$ at 11.00-13.30 O'clock with increasing temperature difference about $7{ }^{\circ} \mathrm{C}$ moving at 15.00 O'clock has closed by cloud for decreasing radiation and temperature. However, not only the solar radiation has been directly affected to temperature difference but also considered about velocity on-field testing for small variable on temperature difference created. 


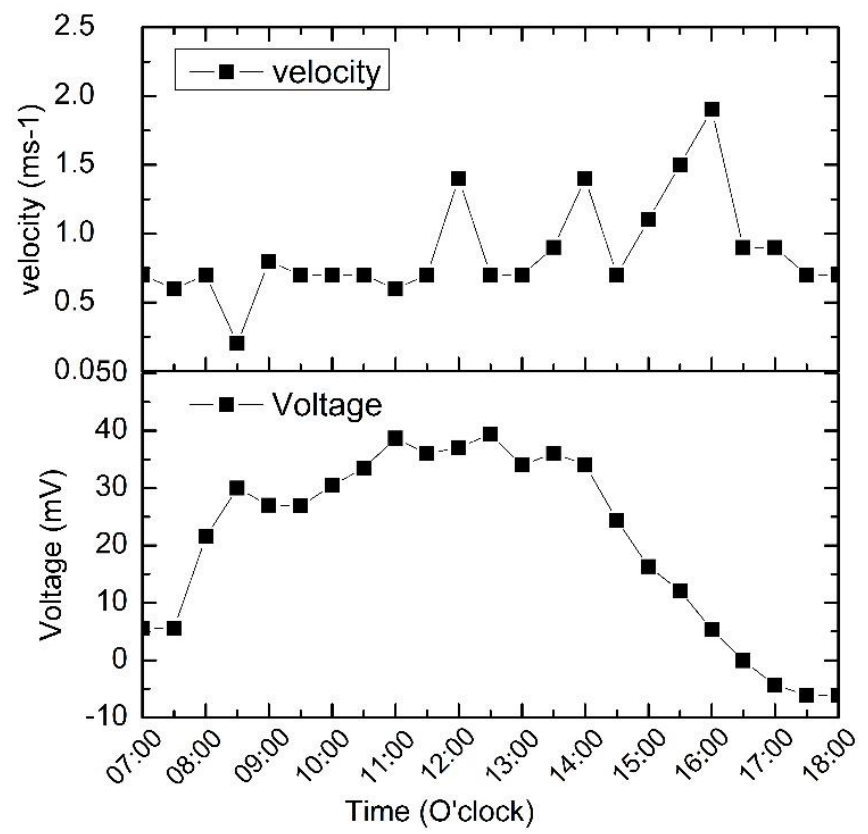

Figure 4: The Relationship of Open Circuit Voltage with Time and Velocityof RTTEG Fieldwork Test.

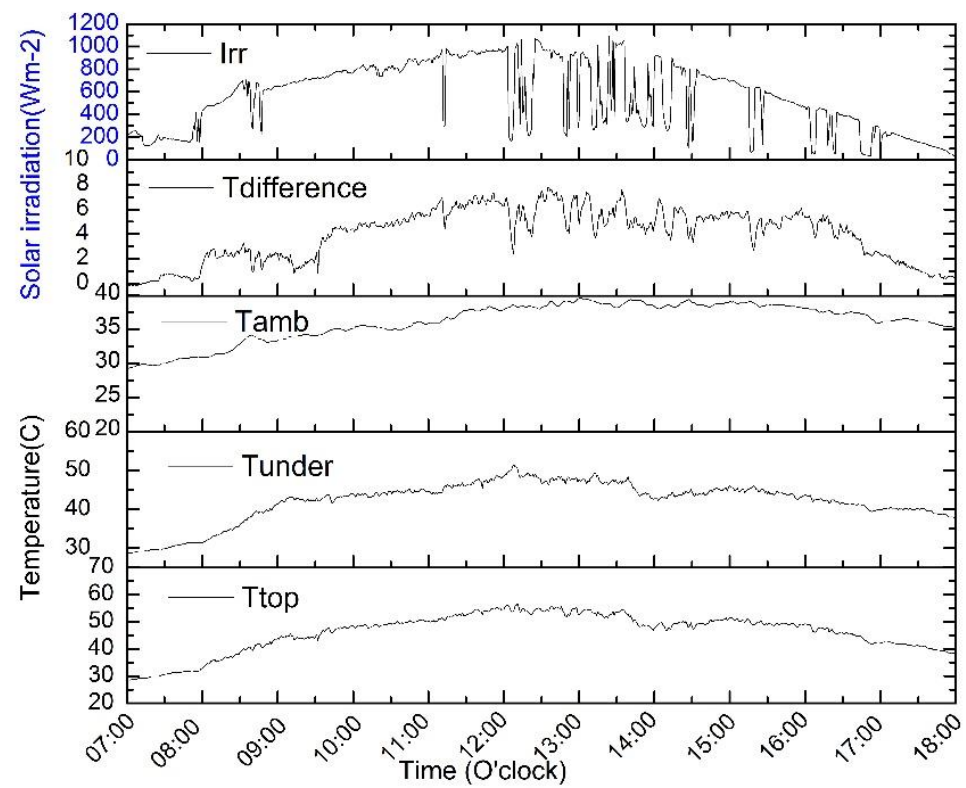

Figure 5: The Relationship of Solar Irradiation with Time and Temperature on Fieldtesting.

The voltage and power of RT-TEG fieldwork test were measured at the $\quad T 5^{\circ} \mathrm{C}$ with vary load resistance $0-50$ $\Omega$. The electrical voltage of both modules was increased with increasing load resistance corresponding with literature data [7-11[ show maximum value about $30 \mathrm{mV}$ as shown in Fig.6.The Current of RT-TEG fieldwork test were decreased when increasing load resistance show the maximum value about $34 \mathrm{~mA}$ at load resistance $1 \Omega$ as shown in Fig.7. The power of RT-TEG fieldwork test were decreased when increasing load resistance show the maximum value about $1,150 \mu \mathrm{W}$ at load resistance $1 \Omega$ as shown in Fig.8. 


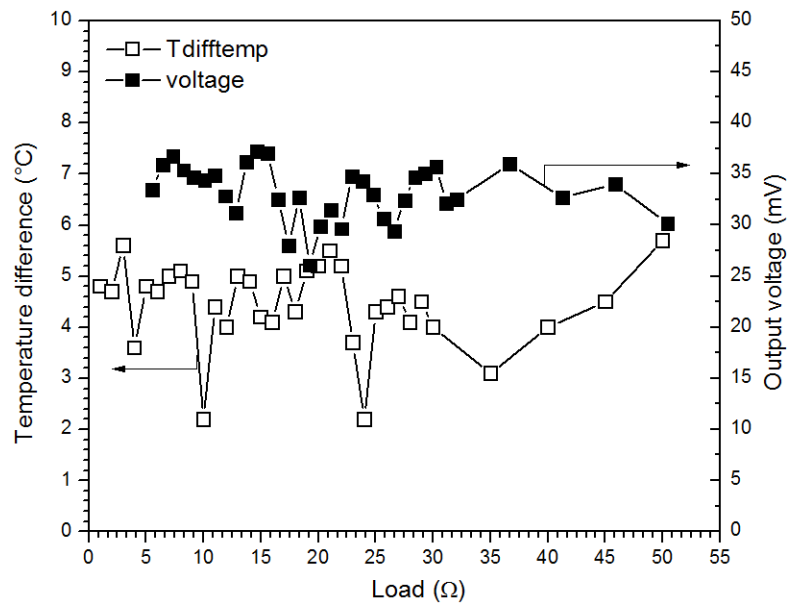

Figure 6: The Relationship of Output Voltage with Time and Temperature Difference on Fieldtesting.

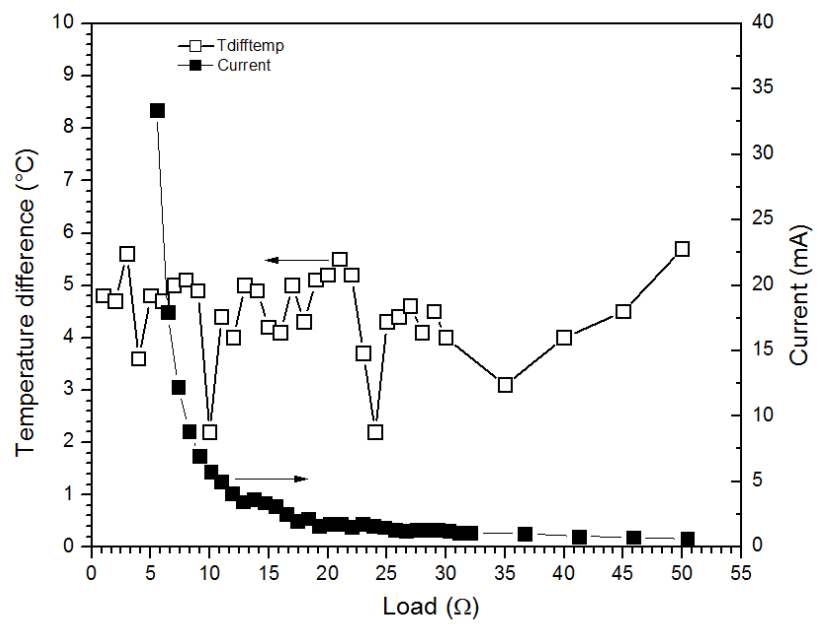

Figure 7: The Relationship of Current with Time and Temperature Difference of RT-TEG Fieldwork Test.

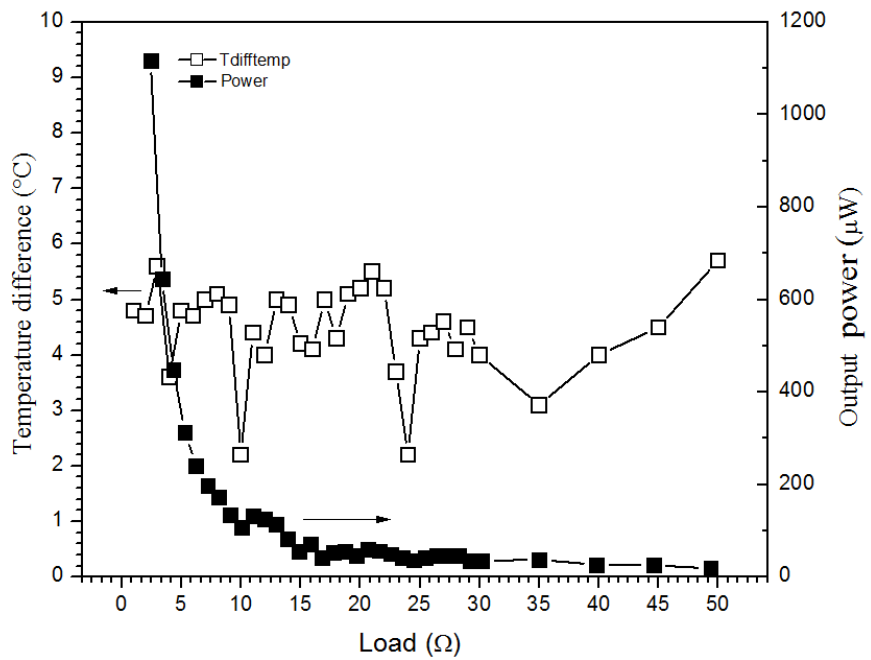

Figure 8: The Relationship of Output Power with Time and Temperature Difference of RT-TEG Fieldwork Test. 


\section{CONCLUSIONS}

The thermoelectric roof tiles (RT-TEG) was built and fieldwork test. Under the test design conditions used here, test results show that the RT-TEG could generate about $1,150 \mu \mathrm{W}$ at load resistance $1 \Omega$ and output voltage $41 \mathrm{mV}$ at velocity $1.5 \mathrm{~ms}-$ 1 and solar intensity of 1,000 Wm-2. Despite its very low electrical conversion efficiency, this concept is particularly important for hot and humidregion. For instance, the RT-TEG could be used as an interesting alternative for enhancing at tic/room ventilation which can help reducing heat accumulation in the house and improving indoor thermal conditions. Due to its simplicity and continuous decrease of TE modules cost, commercial development seems to be promising. Results will be communicated in a forth coming paper.

\section{ACKNOWLEDGMENT}

The authors would like to thank following organizations: Faculty of Engineering, Mahasarkham University and Faculty of Industrial Technology, SakonNakhonRajabhat University for sponsoring sufficient amount of raw materials to support this study. Special gratitude to the staffs of Center of excellence on Alternative Energy (CEAE) and Thermoelectric Research Laboratory, Thailand.

\section{REFERENCES}

1. A. M. Goudarzi, P. Mazandarani, R. Panahi, H. Behsaz, A. Rezania, L. A. Rosendahl, Integration of thermoelectric generators and wood stove to produce heat, hot water, and electrical power, Journal of electronic materials42(7) (2013), 2127 - 2133.

2. S. M. O’Shaughnessy, M. J. Deasy, C. E. Kinsella, J. V. Doyle, A. J. Robinson, Small scale electricity generation from a portable biomass cook stove: Prototype design and preliminary results, Applied Energy 102 (2013) 374-385.

3. S. Shittu, G. Li, Y. G. Akhlaghi, X. Ma, X. Zhao, E. Ayodele, Advancements in thermoelectric generators for enhanced hybrid photovoltaic system performance, Renewable and Sustainable Energy Reviews 109 (2019) 24 - 54.

4. Y. Choi, A. Negash, T. Y. Kim, Waste heat recovery of diesel engine using porous mediumassistedthermoelectricgeneratorequippedwithcustomizedthermoelectric modules, Energy Conversion and Management 197 (2019)., 111902.

5. V. Abbasi, V. S. Tabar, Measurement and evaluation of produced energy by thermoelectric generator in vehicle, Measurement (2019) 107035.

6. H. J. You, H. S. Chu, W. J. Li, W. L. Lee, Influence of different substrate materials on thermoelectric module with bulk legs, Journal of Power Sources 438 (2019) 227055.

7. D. M. Rowe, G. Min, Evaluation of thermoelectric modules for power generation, Journal of power sources 73(2) (1998) 193 198.

8. E. A. Chávez-Urbiola, Y. V. Vorobiev, L. P. Bulat, Solar hybrid systems with thermoelectric generators, Solar energy 86(1) (2012) $369-378$.

9. B. T. Admasu, X. Luo, J. Yao, Effects of temperature non-uniformity over the heat spreader on the outputs of thermoelectric power generation system, Energy conversion and management 76 (2013) 533-540.

10. J. Xiao, T. Yang, P. Li, P. Zhai, Q. Zhang, Thermal design and management for performance optimization of solar thermoelectric generator, Applied Energy 93 (2012) 33-38. 
11. M. Liao, Z. He, C. Jiang, X. A. Fan, Y. Li, F. Qi, A three-dimensional model for thermoelectric generator and the influence of Peltier effect on the performance and heat transfer, Applied Thermal Engineering 133 (2018) 493-500.

12. Sharma, Arun Kumar, and Prashant Baredar. "Roof Tiles Prepared by Using Fly Ash and Analyzing Mechanical Properties." International Journal of Mechanical and Production Engineering Research and Development (IJMPERD) 8.4 (2018) : 595 602.

13. AL Masalha, Ismail., et al. "Experimental Investigations for Improving PV Module Efficiency Using Nanofluid." International Journal of Mechanical and Production Engineering Research and Development (IJMPERD) 10.2 (2020) : 1085-1098

14. Benziger, B., P. Anu Nair, and P. Balakrishnan. "Review paper on thermoelectric airconditioner using peltier modules." International Journal of Mechanical Engineering (IJME) 4.3 (2015) : 49-56

15. Alrwashdeh, Saad S. "An Energy Production Evaluation from PV Arrays with Different Inter-Row Distances." International Journal of Mechanical and Production Engineering Research and Development (IJMPERD) 9.5 (2019): 1-10. 

